06

\title{
Адаптация золь-гель технологии наноструктурированного оксида цинка для целей гибкой электроники
}

\author{
() И.А. Аверин, ${ }^{1}$ И.А. Пронин, ${ }^{1,2,9}$ Н.Д. Якушова, ${ }^{1}$ А.А. Карманов, ${ }^{1}$ Е.А. Алимова, ${ }^{3}$ C.Е. Игошина, ${ }^{1}$ \\ B.А. Мошников, ${ }^{2}$ Е.И. Теруков ${ }^{2,4}$ \\ ${ }^{1}$ Пензенский государственный университет, \\ 440026 Пенза, Россия \\ ${ }^{2}$ Санкт-Петербургский государственный электротехнический университет „ЛЭТИ“, \\ 197376 Санкт-Петербург, Россия \\ ${ }^{3}$ АО „Научно-исследовательский институт электронно-механических приборов“, \\ 440600 Пенза, Россия \\ ${ }^{4}$ Физико-технический институт им. А.Ф. Иоффре РАН, \\ 194021 Санкт-Петербург, Россия \\ ฯ e-mail: pronin_i90@mail.ru
}

Поступило в Редакцию 4 июня 2019 г.

В окончательной редакции 4 июня 2019 г.

Принято к публикации 10 июня 2019 г.

Проанализирована возможность замены классической для золь-гель методов операции высокотемпературного отжига операцией фотоотжига с использованием излучения ультрафиолетового диапазона длин волн. Предложена методика синтеза иерархически организованных пленок оксида цинка в рамках золь-гель технологии, основанная на параллельном совмещении низкотемпературной обработки и УФ-фотоотжига. Проведены спектроскопические исследования качественного состава пленкообразующего золя и наноматериалов на его основе, полученных на различных типах подложек, до и после инициации фотохимических реакций.

Ключевые слова: оксид цинка, фотоотжиг, золь-гель технология, гибкая электроника.

DOI: $10.21883 /$ JTF.2019.12.48492.227-19

\section{Введение}

В настоящее время все большую актуальность приобретают исследования, направленные на создание сенсорных устройств на гибких подложках. На основе материалов гибкой электроники разработаны сенсоры температуры, газов, влажности, давления и др. [1,2]. Спрос на такого рода устройства резко возрастает с развитием мобильных систем контроля состояния окружающей среды в реальном времени с применением радиочастотных меток [3]. При этом отдельный интерес представляет использование сенсоров на гибких подложках в качестве персональных носимых систем для оперативного мониторинга состояния человека. В частности, контроль состава выдыхаемого воздуха человека позволяет диагностировать многие параметры и оценивать степень дисфункции различных органов [4]. Также дешевые газоаналитические системы на гибких подложках рассматриваются в качестве основы для создания „умной“ упаковки скоропортящихся товаров [5].

При этом в качестве перспективных материалов для газосенсорных устройств гибкой электроники рассматриваются наноматериалы, проявляющие хеморезистивные свойства [6], т.е. меняющие свое сопротивление при взаимодействии с анализируемыми газами. Чтобы гарантировать гибкость разрабатываемых устройств, все компоненты (подложка, газочувствительный слой, кон- такты) должны обеспечивать возможность изгиба без любых повреждений или уменьшения сенсорного отклика. В качестве гибкой подложки для газочувствительного слоя предлагается использовать пластиковые (полиэтелен терефталат, полиэтелен нафталат, полистирол, полиамид и др.) [7], бумажные (каолин, бентонит, тальк и др.) [8] и текстильные (листы хлопка и полиэстра, полианилин-нейлон композиты и др.) [9] подложки.

Основная проблема при создании газовых сенсоров на гибких подложках связана с разработкой технологии получения материала газочувствительного слоя. В качестве таких материалов предлагается использовать углеродные нанотрубки [10], слои графена и оксида графена [11], проводящие полимеры [12], металлооксиды [13] и некоторые металлы [14]. Все они обладают собственными характерными достоинствами и недостатками, и в зависимости от конкретного детектируемого газа и условий эксплуатации конечного устройства целесообразным представляется использование того или иного материала. Однако металлооксиды, такие как $\mathrm{SnO}_{2}, \mathrm{ZnO}$, $\mathrm{TiO}_{2}, \mathrm{WO}_{3}$ и т. д., уже достаточно давно зарекомендовали себя с позиции перспективных материалов для газовой сенсорики и фотокатализа $[15,16]$. Их несомненным преимуществом является широкий спектр детектируемых газов (включая, $\mathrm{NO}_{2}, \mathrm{H}_{2}, \mathrm{CO}$, пары этанола, аммиака и т.д.) и высокие значения сенсорного отклика. 


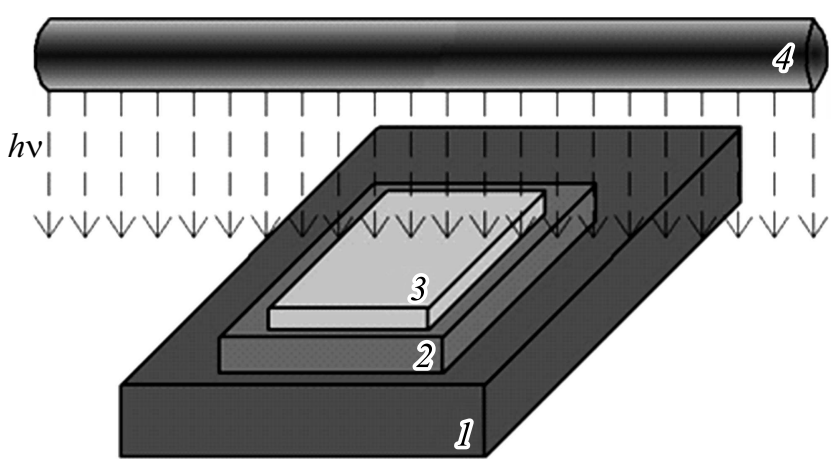

Рис. 1. Схема эксперимента по совмещению низкотемпературной обработки и УФ-фотоотжига иерархически организованных пленок $\mathrm{ZnO}: 1$ - плоский металлический нагреватель, 2 - подложка, 3 - пенка $\mathrm{ZnO}, 4$ - источник УФ-излучения.

Оксид цинка является типичным представителем широкозонных полупроводниковых металлооксидов. За счет проявления комплекса уникальных электрофизических, адсорбционных и каталитических свойств при переходе в наносостояние или при наноструктурировании он стал основой для создания чувствительных элементов различного рода газовых сенсоров, в том числе на основе недавно обнаруженного термовольтаического эффекта $[17,18]$.

Сдерживающим фактором, ограничивающим использование металлооксидов (и оксида цинка в частности) в гибкой электронике, является отсутствие возможности использования высокой температуры (обычно > $300^{\circ} \mathrm{C}$ ) как при синтезе наноматериалов, так и в процессе работы сенсора.

Цель настоящей работы - разработка методики низкотемпературного синтеза $\mathrm{ZnO}$ в рамках золь-гель технологии и исследование особенностей его структуры и состава. При этом анализируется возможность замена классической для золь-гель методов операции высокотемпературного отжига [19] операцией фотоотжига с использованием излучения ультрафиолетового диапазона длин волн. О возможности такого рода подхода применительно к созданию слоев тонкопленочных полевых транзисторов впервые сообщалось в работе [20].

\section{Методика эксперимента}

Синтез оксида цинка проводился в рамках зольгель технологии с учетом модификации разработанной ранее методики [21]. На первом этапе синтеза $10 \mathrm{~g}$ дигидрат ацетата цинка $-\left(\mathrm{CH}_{3} \mathrm{COO}\right)_{2} \mathrm{Zn} \cdot 2 \mathrm{H}_{2} \mathrm{O}$ смешивали с $20 \mathrm{ml}$ 2-метоксиэтанола - $\mathrm{CH}_{3} \mathrm{OCH}_{2} \mathrm{CH}_{2} \mathrm{OH}$ и $3.2 \mathrm{ml}$ 2-аминоэтанола - $\mathrm{HOCH}_{2} \mathrm{CH}_{2} \mathrm{NH}_{2}$ в круглодонной колбе и перемешивали в течение $15 \mathrm{~min}$ при комнатной температуре $\left(25^{\circ} \mathrm{C}\right)$. На втором этапе раствор перемешивали в течение $60 \mathrm{~min}$ при температуpe $60^{\circ} \mathrm{C}$ с помощью магнитной мешалки, обеспечивая полное растворение ацетата цинка. Далее полученный золь созревал в течение $24 \mathrm{~h}$ при нормальных условиях. Формирование $\mathrm{ZnO}$ в виде иерархически организованных пленок проводилось методом центрифугирования на подложках из монокристаллического кремния и алюминиевой фольги. На последнем этапе синтеза в течение $1 \mathrm{~h}$ проводилась операция УФ-фотоотжига, которую в ряде экспериментов (рис. 1) совмещали с низкотемпературным отжигом $\left(<110^{\circ} \mathrm{C}\right)$. При этом в качестве источника УФ-излучения использовалась ртутная лампа с максимумами спектральной интенсивности при 185 и $254 \mathrm{~nm}$. Для низкотемпературной обработки образцов применялся плоский нагреватель открытого типа с металлической поверхностью. Его температуру и температуру образцов, расположенных на нем, которые были удалены от источника УФ-излучения на расстояние $3-5 \mathrm{~cm}$, контролировали с использованием пирометра.

Качественный состав синтезируемых пленок оксида цинка, а также используемого для их синтеза пленкообразующего золя определялся методом ИК-спектроскопии. Измерения проводились на ИК-Фурье-спектрометре ФСМ 1201 (ООО „Инфраспек“, Россия) в спектральном диапазоне $450-4500 \mathrm{~cm}^{-1}$ с разрешением $4 \mathrm{~cm}^{-1}$. Исследование золя было проведено в рамках метода многократного нарушения полного внутреннего отражения (МНПВО) с использованием кюветы МНПВО36 из ZnSe. Инфракрасные спектры иерархически организованных пленок $\mathrm{ZnO}$ до и после операции УФ-фотоотжига были получены с использованием приставки зеркального отражения П3О10.

Спектры оптического пропускания пленкообразующего золя и прекурсоров, используемых при его синтезе (2-метоксиэтанола и 2-аминоэтанола), были измерены на спектрофотометре СФ-56 (ОКБ Спектр, СанктПетербург), применяя кварцевые кюветы и дистиллированную воду в качестве образца сравнения.

Структура поверхности образцов после этапа отжига была исследована с помощью растрового электронного микроскопа VRGA 3 SBH (TESCAN, Чехия) с использованием детектора отраженных электронов.

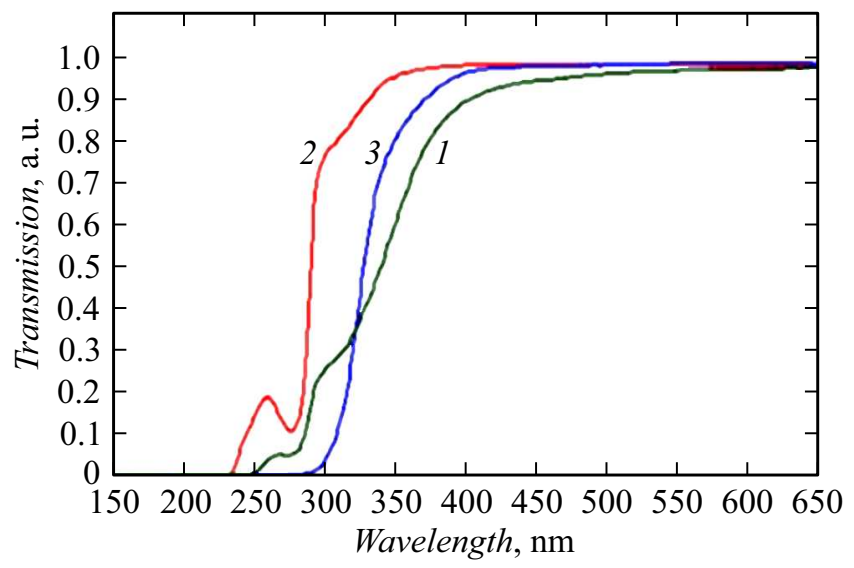

Рис. 2. Оптические спектры пропускания: 1 - 2-метоксиэтанола; 2 - 2-аминтоэтанола; 3 - пленкообразующего золя. 


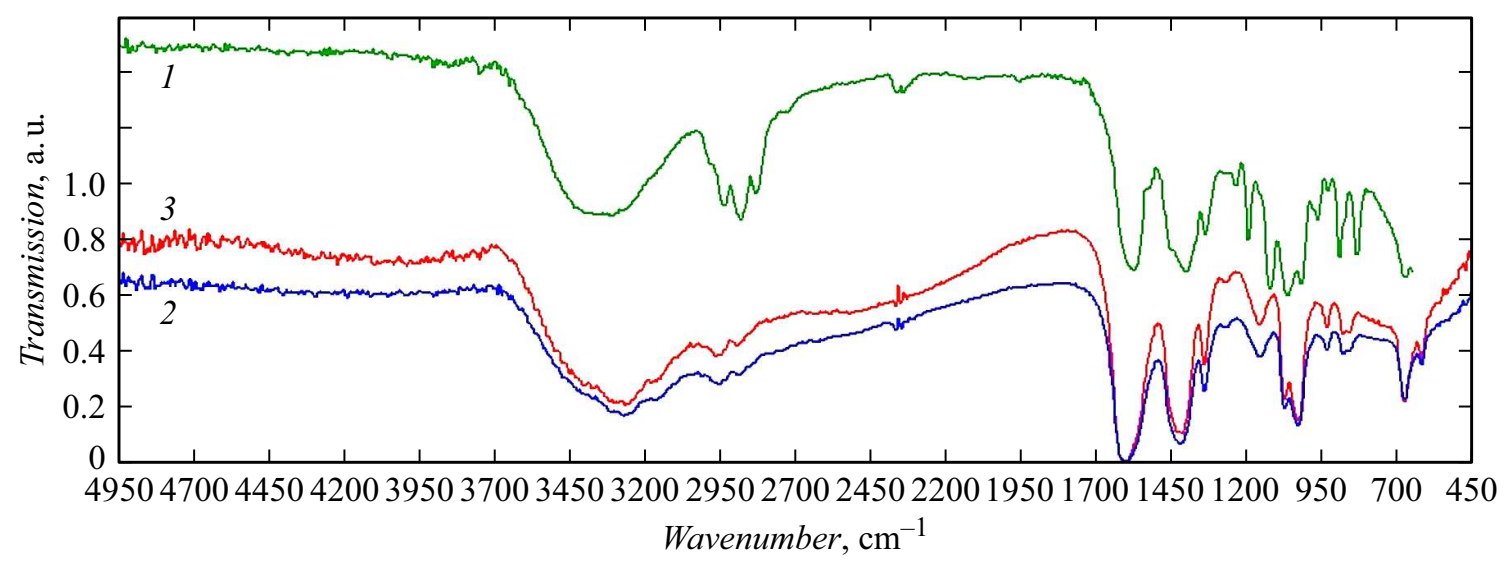

Рис. 3. Инфракрасные спектры пропускания пленкообразующего золя (1) и иерархически организованных пленок ZnO на поверхности алюминиевой фольги: 2 - до операции УФ-фотоотжига; 3 - после операции УФ-фотоотжига.

\section{Результаты и обсуждение}

В рамках первого этапа исследований были измерены спектры оптического пропускания излучения УФ и видимого диапазона длин волн через пленкообразующий золь и входящие в его состав прекурсоры (рис. 2). Основной целью являлась оценка взаимодействия УФ-излучения и анализируемой золь-гель наносистемы.

Анализ полученных оптических спектров пропускания показывает сильное поглощение пленкообразующим золем излучения в диапазоне длин волн 190-300 nm, которое представляет собой интегральный вклад от поглощения 2-аминоэтанола и 2-метоксиэтанола. При этом видно, что первый из указанных прекурсоров имеет нулевую полосу пропускания в диапазоне 190-290 nm, a для второго характерно наличие широкой полосы поглощения в области 190-240 nm и локального минимума пропускания около $275 \mathrm{~nm}$. Наличие данных полос и пиков поглощения является ключевой особенностью прекурсоров, используемых в рамках рассматриваемой методики синтеза. Данная особенность в свою очередь обусловливает принципиальную возможность протекания фотоактивационных процессов при проведении УФ-фотоотжига с использованием ртутной лампы с максимумами спектральной интенсивности при 185 и $254 \mathrm{~nm}$. Полученные результаты согласуются с экспериментальными данными и выводами работы [20] относительно влияния состава прекурсоров на фотоактивационные процессы, хотя и требуют дополнительной проверки, затрагивающей использование реагентов со слабым поглощением в УФ-области.

В рамках второго этапа исследований были измерены ИК-спектры пленкообразующего золя (для удобства восприятия спектр сдвинут относительно нулевой точки по оси ординат) и оксида цинка, синтезированного на его основе в виде тонких иерархически организованных пленок на поверхности алюминиевой фольги (рис. 3). Выбор данного типа подложек обусловлен с одной стороны удобством при проведении спектроскопических исследований, а с другой стороны их в известной мере гибкостью.

Анализ представленных данных показывает, что ИК-спектры образцов до и после операции УФфотоотжига содержат идентичные полосы и пики поглощения, по большей части совпадающие с модами, характерными для пленкообразующего золя [22]. В целом на анализируемых спектрах можно выделить характерные для 2-метоксиэтанола и 2-аминоэтанола минимумы пропускания, отвечающие колебаниям углеродного скелета $\mathrm{C}-\mathrm{C}$, колебаниям связям $\mathrm{R}-\mathrm{O}-\mathrm{H}$ и $\mathrm{C}-\mathrm{O}-\mathrm{H}$ (где $\mathrm{R}$ - углеводородный радикал), а также $\mathrm{CH}_{2}-, \mathrm{CH}_{3}$ и $\mathrm{NH}_{2}$-групп соответственно. При этом о присутствии в золе растворенного ацетата цинка можно судить по наличию пиков поглощения при 940 и $970 \mathrm{~cm}^{-1}$, отвечающих колебаниям $\mathrm{R}-\mathrm{COO}^{-}$группы. Углекислый газ также активно растворяется в 2-метоксиэтаноле, а следовательно, и в пленкообразующем золе, о чем можно судить по наличию максимума поглощения при $2360 \mathrm{~cm}^{-1}$. Обобщенные результаты спектроскопических исследований синтезированных материалов представлены в таблице и хорошо согласуются с данными более ранней работы [22].

Сопоставление ИК-спектров иерархически организованных пленок до и после проведения операции УФфотоотжига позволяет сделать вывод о том, что физикохимические процессы, связанные с существенной перестройкой существующих химических связей или с образованием новых связей, не протекают. Наблюдается лишь частичная десорбция органических растворителей, о которой можно судить по увеличению пропускания ИК-излучения во всем спектральном диапазоне, а также изменения, связанные с нанесением пленкообразующего золя на подложку методом центрифугирования. В частности, наблюдаемый переход от двух пиков поглощения при 1120 и $1200 \mathrm{~cm}^{-1}$, характерный для пленкообразующего золя, к одному пику при $1180 \mathrm{~cm}^{-1}$, отвечающему образцам до и после УФ-фотоотжига, можно связать с процессом частичного гелеобразования, сопровождаю- 
Интерпретация ИК-спектров пленкообразующего золя и иерархически организованных пленок на его основе

\begin{tabular}{c|l}
\hline Положение линий поглощения, $\mathrm{cm}^{-1}$ & \multicolumn{1}{c}{ Интерпретация } \\
\hline 620,680 & Веерное $\mathrm{NH}_{2}$ \\
740 & Деформационные $\mathrm{R}-\mathrm{O}-\mathrm{H}$ \\
840,890 & Неплоские деформационные колебания $\mathrm{N}-\mathrm{H}$, валентые $\mathrm{C}-\mathrm{C}$ \\
940,970 & $\mathrm{R}-\mathrm{COO}^{-}$группа ацетата \\
1040,1070 & Валентные $\mathrm{C}-\mathrm{CO}$ и деформационные O-H первичного спирта \\
1120 & Валентные $\mathrm{C}-\mathrm{O}-\mathrm{C}$ \\
$1160-1200$ & \\
1340 & Деформационные $\mathrm{C}-\mathrm{O}-\mathrm{H}$, валентные симметричные $\mathrm{C}=\mathrm{O}$ \\
1620 & Деформационные $\mathrm{H}-\mathrm{O}-\mathrm{H}$ \\
2360 & Атмосферный CO 2 \\
2820 & Валентные О-CH 3 \\
2890 & Валентные симметричные $\mathrm{CH}_{3}$ \\
2940 & Валентные асимметричные $\mathrm{CH}_{2}$ \\
$3050-3650$ & Валентные симметричные колебания $\mathrm{O}-\mathrm{H}$
\end{tabular}

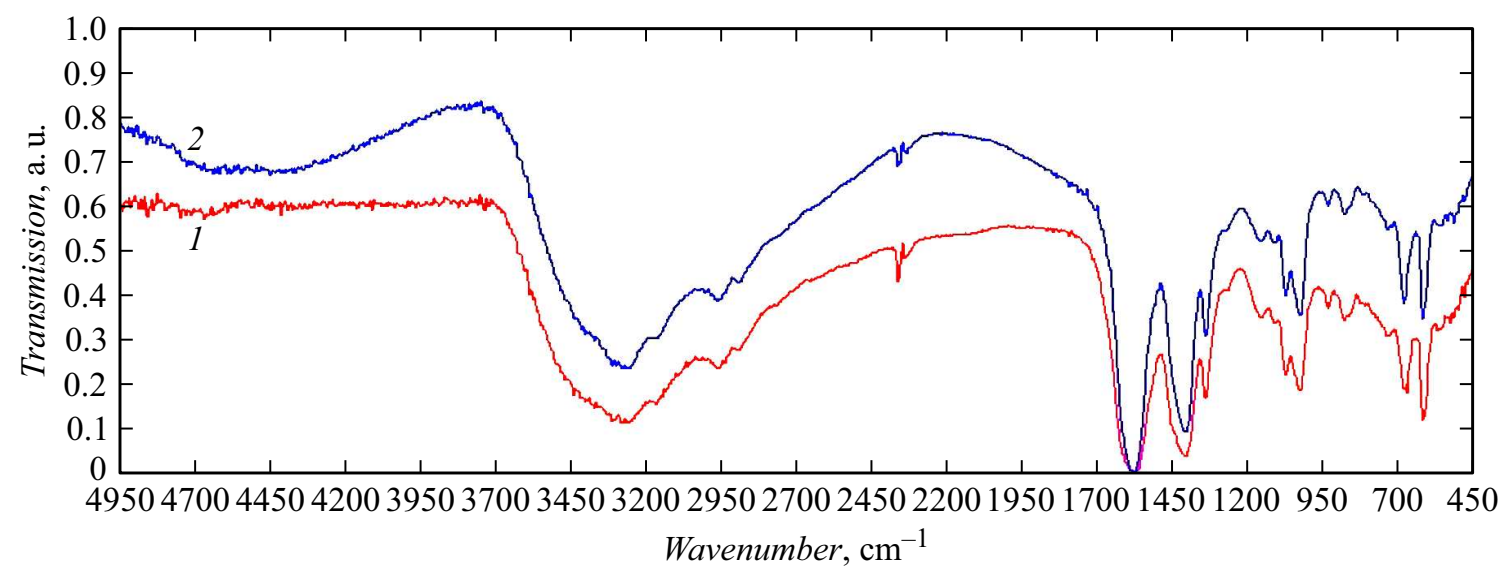

Рис. 4. Инфракрасные спектры иерархически организованных пленок $\mathrm{ZnO}$ на поверхности кремния: 1 - до операции фотоотжига, 2 - после операции УФ-фотоотжига.

щимся перестройкой химических связей в комплексах цинка [23].

В рамках третьего этапа исследования были измерены ИК-спектры иерархически организованных пленок оксида цинка на поверхности монокристаллического кремния (рис. 4).

Согласно полученным экспериментальным данным, ИК-спектры пленок $\mathrm{ZnO}$ на кремниевых подложках и на алюминиевой фольге практически идентичны. При этом для образцов на $\mathrm{Si}$ заметна более яркая выраженность пика поглощения при $620 \mathrm{~cm}^{-1}$, который в данном случае отвечает не только веерным колебаниям $\mathrm{NH}_{2}$, но и валентным симметричным колебаниям связей $\mathrm{Si}-\mathrm{Si}$-подложки. Также дополнительно наблюдается колебательная мода при $1110 \mathrm{~cm}^{-1}$ со слабой интенсивностью, которая характеризует валентные ассиметричные колебания $\mathrm{Si}-\mathrm{O}-\mathrm{Si}$-связей [24]. Ключевой особенностью ИК-спектров иерархически организованных пленок оксида цинка после проведения операции УФ-фотоожига является возникновение широкой полосы поглощения в спектральном диапазоне $3900-4900 \mathrm{~cm}^{-1}$. Данная колебательная мода в целом не характерна для пленок, полученных в рамках золь-гель технологии с использованием высокотемпературного нагрева, и ее существование, наиболее вероятно, связано с фотоактивационными процессами в золь-гель наносистемах. Исходя из относительно большой интенсивности и протяженности, можно предположить, что она отвечает второму обертону

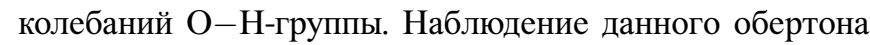
в ИК-спектрах пленок оксида цинка на кремниевых подложках может быть объяснено „отрывом“ связанных ОН-групп с выделением воды в свободном виде.

Остальные процессы, протекающие в образцах на кремниевых подложках при УФ-фотоотжиге, аналогичны наблюдаемым на алюминиевой фольге. В частности, по увеличению пропускания ИК-излучения во всем спектральном диапазоне за исключением моды при $1620 \mathrm{~cm}^{-1}$, можно сделать вывод о частичной десорбции органических компонентов золя. По всей видимости, энергии УФ-излучения от используемой ртут- 


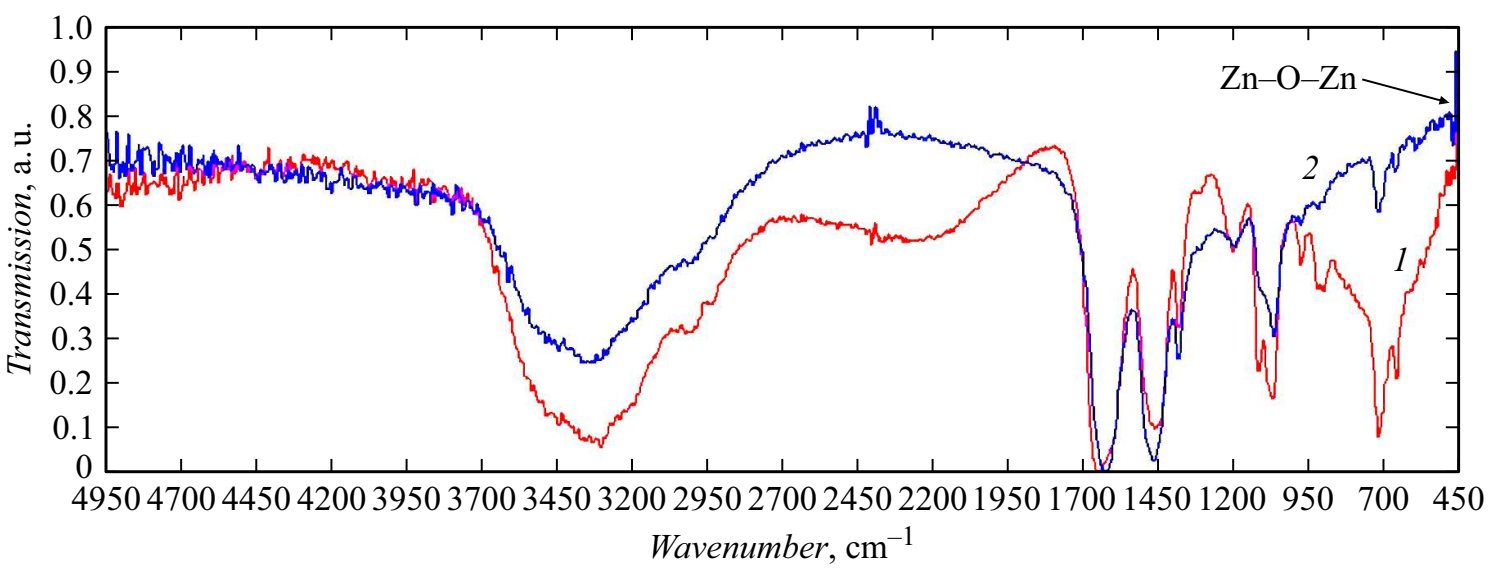

Pис. 5. Инфракрасные спектры иерархически организованных пленок $\mathrm{ZnO}$ на поверхности алюминиевой фольги: 1 - до операции фотоотжига; 2 - после комбинированной операции низкотемпературной обработки и УФ-фотоотжига.

ной лампы не достаточно для десорбции из структуры пленки воды в несвязанном виде, которой отвечают деформационные Н-O-Н-колебаниям. По данным литературных источников, полная десорбция воды наблюдается только при температуре около $600^{\circ} \mathrm{C}$, что не соответствует условиям проведенного исследования. Следует отметить, что использование ртутной лампы в представленной на рис. 1 геометрии эксперимента не сопровождалось значительным дополнительным тепловым нагревом. По данным пирометрических измерений, температура пленок $\mathrm{ZnO}$ не превышала $35^{\circ} \mathrm{C}$ в независимости от типа исследуемой подложки. Отсутствие дополнительной тепловой энергии в анализируемой золь-гель наносистеме не позволило полностью удалить органический растворитель из структуры пленки и обеспечить процесс конденсации, сопровождающийся образованием $\mathrm{Zn}-\mathrm{O}-\mathrm{Zn}$-сетей. Данное наблюдение полностью согласуется с результатами работы [20], в которой сделано предположение, что для формирования функциональных слоев тонкопленочных полевых транзисторов требуется нагрев до $150-180^{\circ} \mathrm{C}$.

В рамках четвертого этапа исследований проводились измерения ИК-спектров пропускания иерархически организованных пленок оксида цинка, полученных при параллельном проведении операций УФ-фотоожига и низкотемпературного термического отжига (рис. 5).

Анализ представленных на рис. 5 ИК-спектров подтверждает вышеуказанное предположение о необходимости подвода дополнительной тепловой энергии в золь-гель наносистемы при проведении УФ-фотоожига. При этом, согласно данным ИК-спектроскопии для инициации фотохимических реакций по расколу алкокси групп и активации атомов металла и кислорода для формирования $\mathrm{Zn}-\mathrm{O}-\mathrm{Zn}$-связей, достаточно нагрева до температур менее $110^{\circ} \mathrm{C}$ (для образцов, соответствующих кривой 2 на рис. 5, температура по данным пирометрических измерений составляла $80^{\circ} \mathrm{C}$ ). В данном случае о расколе алкокси групп можно судить по значительному уменышению интенсивности полосы по- глощения при $740 \mathrm{~cm}^{-1}$, отвечающей деформационным $\mathrm{R}-\mathrm{O}-\mathrm{H}$-колебаниям, а также по исчезновению пика поглощения при $1120 \mathrm{~cm}^{-1}$, соответствующего валентным колебаниям $\mathrm{C}-\mathrm{O}-\mathrm{C}-$ связей. О полезном воздействии УФ-излучения, заключающемся в активации реакций конденсации и уплотнения пленок, можно утверждать, исходя из практически полного исчезновения пиков поглощения при 940 и $970 \mathrm{~cm}^{-1}$, отвечающих $\mathrm{R}-\mathrm{COO}^{-}$-группе ацетата цинка, и возникновения моды при $470 \mathrm{~cm}^{-1}$, которая достоверно идентифицируется, как относящаяся к колебаниям связей $\mathrm{Zn}-\mathrm{O}-\mathrm{Zn}$.

\section{Заключение}

Таким образом, в работе предложена и апробирована методика синтеза иерархически организованных пленок оксида цинка в рамках золь-гель технологии, основанная на параллельном совмещении низкотемпературной обработки и фотоотжига с использованием излучения ультрафиолетового диапазона длин волн. На основе данных ИК-спектроскопии показано, что для инициации фотохимических реакций в анализируемой золь-гель наносистеме, приводящих к образованию $\mathrm{Zn}-\mathrm{O}-\mathrm{Zn}$-связей, необходимо и достаточно воздействие УФ-излучения с подводом незначительной дополнительной тепловой энергии. Полученные результаты представляют научный и практический интерес для развития направления создания функциональных слоев газовых сенсоров на гибких подложках.

\section{Финансирование работы}

Работа выполнялась при финансовой поддержке Министерства образования и науки РФ (проект № 16.897.2017/ПЧ), РФФИ в рамках научного проекта № 19-08-00924, а также стипендии президента РФ (СП3800.2018.1). 


\section{Конфликт интересов}

Авторы заявляют, что у них нет конфликта интересов.

\section{Список литературы}

[1] Kim J., Yoo H., Ba V.A.P., Shin N., Hong S. // Sci. Reps. 2018. Vol. 8. 11958. DOI: 10.1038/s41598-018-30481-y

[2] Kou H., Zhang L., Tan Q., Liu G., Dong H., Zhang W., Xiong J. // Sci. Rep. 2019. Vol. 9. 3916.

DOI: 10.1038/s41598-019-40828-8

[3] Abad E., Zampolli S., Marco S., Scorzoni A., Mazzolai B., Juarros A., Gómez D., Elmi I., Cardinali G.-C., Gómez J.M., Palacio F., Cicioni M., Mondini A., Becker T., Sayhan I. // Sensor Actuat. B-Chem. 2007. Vol. 127. P. 2-7. DOI: 10.1016/j.snb.2007.07.007

[4] Konvalina G., Haick H. // Acc. Chem. Res. 2014. Vol. 47. P. $66-76$. DOI: $10.1021 / \operatorname{ar} 400070 \mathrm{~m}$

[5] Koskela J., Sarfraz J., Ihalainen P., Määttänen A., Pulkkinen P., Tenhu H., Nieminen T., Kilpelä A., Peltonen J. // Sensor Actuat. B-Chem. 2015. Vol. 218. P. 8996. DOI: $10.1016 /$ j.snb.2015.04.093

[6] Chiu S.-W., Tang K.-T. // Sensors. 2013. Vol. 13. P. 14214 14247. DOI: $10.3390 / \mathrm{s} 131014214$

[7] Briand D., Oprea A., Courbat J., Bârsan N. // Mater. Today. 2011. Vol. 14. P. 416-423. DOI: $10.1016 / \mathrm{S} 1369-7021(11) 70186-9$

[8] Yang G., Lee C., Kim J., Ren F., Pearton S.J. // Phys. Chem. Chem. Phys. 2013. Vol. P. 1798-1801. DOI: $10.1039 / \mathrm{C} 2 \mathrm{CP} 43717 \mathrm{~A}$

[9] Han J.-W., Kim B., Meyyappan M., Li. J // Appl. Phys. Lett. 2013. Vol. 102. P. 193104. DOI: $10.1063 / 1.4805025$

[10] Parikh K., Cattanach K., Rao R., Suh D.-S., Wu A., Manohar S.K. // Sensor Actuat. B-Chem. 2006. Vol. 113. P. 55-63. DOI: 10.1016/j.snb.2005.02.021

[11] Lee C., Ahn J., Lee K.B., Kim D., Kim J. // Thin Solid Films. 2012. Vol. 520. P. 5459-5462. DOI: 10.1016/j.tsf.2012.03.095

[12] Janata J., Josowicz M. // Nat. Mater. 2003. Vol. 2. P. 19-24. DOI: $10.1038 /$ nmat 768

[13] Comini E. // Sensors. 2013. Vol. 13. P. 10659-10673. DOI: $10.3390 / \mathrm{s} 130810659$

[14] Kim W., Jang B., Lee H.-S., Lee W. // Sensor Actuat. B-Chem. 2016. Vol. 224. P. 547-551. DOI: 10.1016/j.snb.2015.10.092

[15] Пронин И.А., Канева Н.В., Божсинова А.С., Аверин И.А., Папазова К.И., Димитров Д.Ц., Мошников В.А. // Кинетика и катализ. 2014. Т. 55. № 2. С. 176.

[16] Fedorov F., Vasilkov M., Lashkov A., Varezhnikov A., Fuchs D., Kübel Ch., Bruns M., Sommer M., Sysoev V. // Sci. Rep. 2017. Vol. 7. P. 9732. DOI: 10.1038/s41598-017-10495-8

[17] Dimitrov D.Tz., Nikolaev N.K., Papazova K.I., Krasteva L.K., Pronin I.A., Averin I.A., Bojinova A.S., Georgieva A.Ts., Yakushova N.D., Peshkova T.V., Karmanov A.A., Kaneva N.V., Moshnikov V.A. // Appl. Surf. Sci. 2017. Vol. 392. P. 95-108. DOI: 10.1016/j.apsusc.2016.08.049

[18] Пронин И.А., Якушова Н.Д., Димитров Д.Ц., Крастева Л.К., Папазова К.И., Карманов А.А., Аверин И.А., Георгиева А.Ц., Мошников В.А., Теруков Е.И. // Письма в ЖТФ. 2017. Т. 43. Вып. 18. С. 11-16.

[19] Мошников В.А., Таиров Ю.М., Хамова Т.В., Шилова О.А. Золь-гель технология микро- и нанокомпозитов. СПб: Химиздат, 2013. 304 c.
[20] Kim Y.-H., Heo J.-S., Kim T.-H., Park S., Yoon M.-H., Kim J., Oh M.S., Yo G.-R., Noh Y.-Y., Park S.K. // Nature. 2012. Vol. 489. P. $128-133$. DOI: $10.1038 /$ nature 11434

[21] Pronin I.A., Averin I.A., Yakushova N.D., Dimitrov D.T., Krasteva L.K., Papazova K.I., Chanachev A.S., Bojinova A.S., Georgieva A.T., Moshnikov V.A. // Sensor Actuat. A-Phys. 2014. Vol. 206. P. 88-96. DOI: 10.1016/j.sna.2013.11.035

[22] Крупкин Е.И., Аверин И.А., Пронин И.А., Карманов А.А., Якушова Н.Д. // Нано- и микросистемная техника. 2019. T. 21. № 1. C. 23-34.

[23] Gómez-Nuñez A., Alonso-Gil S., López C., Roura P., Vilà A. // J. Phys. Chem. C 2017. Vol. 121. P. 23839-23846. DOI: 10.1021/acs.jpcc.7b09935

[24] Аверин И.А., Карманов А.А., Мочников В.А., Пронин И.А., Игошина С.Е., Сигаев А.П., Теруков Е.И. // ФТТ. 2015. Т. 57. Вып. 12. С. 2304-2312. 